CZASOPISMO INŻYNIERII LA¿DOWEJ, ŚRODOWISKA I ARCHITEKTURY JOURNAL OF CIVIL ENGINEERING, ENVIRONMENT AND ARCHITECTURE

JCEEA, t. XXXIII, z. 63 (4/16), październik-grudzień 2016, s. 87-96

Bernardeta DĘBSKA ${ }^{1}$

Lech LICHOŁAI ${ }^{2}$

\title{
PORÓWNANIE WYBRANYCH WŁAŚCIWOŚCI ZAPRAW ŻYWICZNYCH ZAWIERAJĄCYCH ODPADOWE TWORZYWA SZTUCZNE
}

\begin{abstract}
Racjonalna gospodarka odpadami stanowi jeden z priorytetowych kierunków szeroko rozumianej ochrony środowiska. Fakt umiejętnego zagospodarowania odpadów jest także ważny w kontekście zrównoważonego rozwoju społeczeństw. Do odpadów wyjątkowo uciążliwych dla środowiska zaliczyć należy tworzywa sztuczne. Wzrastające nieustannie ilości tego typu odpadów powodują występowanie problemów zarówno ekologicznych, jak i gospodarczych, co związane jest ze słabą biodegradacją tworzyw. Odpady te zaczęto wykorzystywać do produkcji materiałów budowlanych. Badania nad zagospodarowaniem odpadów z tworzyw sztucznych prowadzone są obecnie w różnych ośrodkach naukowych na świecie. W literaturze można znaleźć opisy wykorzystania odpadów m.in. polietylenu i polipropylenu, styropianu, poliuretanów, poliwęglanu, poliamidu, czy poli(chlorku winylu), jako modyfikatorów betonów i zapraw cementowych. W niniejszym artykule przedstawiono wyniki porównania wybranych właściwości czterech serii zapraw żywicznych zawierających różne odpady tworzyw sztucznych tj.: polipropylen $(\mathrm{PP})$, polietylen $(\mathrm{PE})$, piankę poliuretanową (PU) oraz ekspandowany polistyren (EPS). Odpady te pochodziły odpowiednio z kubków po jogurtach, pianki podkładowej pod panele, pianki montażowej oraz płyt styropianowych. Zostały one rozdrobnione i stanowiły częściowy zamiennik kruszywa w zaprawach epoksydowych. Zbadano takie właściwości zapraw, jak: wytrzymałość na zginanie i ściskanie, gęstość objętościowa oraz nasiąkliwość. Wskazano materiał odpadowy, umożliwiający otrzymanie zaprawy cechującej się najkorzystniejszymi wartościami oznaczonych parametrów. Na podstawie uzyskanych wyników badań stwierdzono, że nawet przy $20 \%$ substytucji piasku odpadami tworzyw sztucznych, można otrzymać kompozyt charakteryzujący się bardzo dobrymi parametrami wytrzymałościowymi oraz niską nasiąkliwością wodą.
\end{abstract}

Słowa kluczowe: zaprawy epoksydowe, odpady tworzyw sztucznych, wytrzymałość, nasiąkliwość

1 Autor do korespondencji / corresponding author: Bernardeta Dębska, Politechnika Rzeszowska, Zakład Budownictwa Ogólnego, ul. Poznańska 2, 35-959 Rzeszów; tel. 178651323; bdebska@prz.edu.pl

${ }^{2}$ Lech Lichołai, Politechnika Rzeszowska, Zakład Budownictwa Ogólnego, ul. Poznańska 2, 35-959 Rzeszów; tel. 178651327; Lech.Licholai@prz.edu.pl 


\section{Wprowadzenie}

Plastik, który można nazwać jednym z najbardziej innowacyjnych materiałów dwudziestego wieku, stał się produktem wszechobecnym. W ostatnich latach na całym świecie obserwuje się znaczny wzrost zużycia tego typu tworzyw sztucznych, co powoduje również zwiększenie wytwarzania odpadów tych materiałów [1].

Udział procentowy poszczególnych typów odpadów z tworzyw sztucznych przedstawia się następująco [2]: polietylen niskiej gęstości (LDPE) - 23\%, polietylen wysokiej gęstości (HDPE) - 17,3\%, polipropylen (PP) - 18,5\%, polistyren (PS) $-12,3 \%$, chlorek winylu (VC) - 10,7\%, poli(tereftalan etylenu) (PET) $8,5 \%$, inne $-9,7 \%$. Ze względu na uniwersalność wielu właściwości tworzyw sztucznych wzrost ich wykorzystania jest pożądany. Z kolei wśród niekorzystnych zjawisk związanych ze stosowaniem tworzyw sztucznych wymienia się fakt, że na etapie produkcji wykorzystywane są często związki toksyczne, a także takie, których działanie na organizmy żywe nie jest jeszcze do końca poznane [2]. Zaleta, jaką jest odporność tworzyw sztucznych na działanie wielu środków chemicznych i czynników atmosferycznych, zamienia się w wadę w momencie, gdy polimery stają się odpadem, gdyż produkty te tylko w niewielkim stopniu ulegają degradacji. Odpady z tworzyw sztucznych powodują więc występowanie problemów zarówno ekologicznych, jak i gospodarczych. Stanowią one zagrożenie dla wszystkich komponentów środowiska, tj. powierzchni ziemi, hydrosfery, biosfery i atmosfery. Z tych względów racjonalna gospodarka odpadami należy do priorytetowych kierunków szeroko rozumianej ochrony środowiska.

Na utylizację odpadów z tworzyw sztucznych składają się następujące etapy [3]: zbiórka odpadów, sortowanie, mycie, recykling. Ostatni etap, czyli recykling, może być realizowany na różne sposoby: recykling mechaniczny, recykling chemiczny, spalanie.

Warto podjąć próbę zagospodarowania odpadów polimerowych w sposób wybiegający poza przyjęte schematy. Do takich metod można zaliczyć użycie odpadów z tworzyw w procesie otrzymywania mas asfaltowych czy kompozytów, w tym kompozytów polimerobetonowych. Niska waga, wytrzymałość, odporność na działanie różnych roztworów korozyjnych, doskonałe właściwości termo- i elektroizolacyjne - to cechy odpadowych tworzyw sztucznych, które mogą być wykorzystane do otrzymywania innowacyjnych materiałów kompozytowych, wpisujących się w założenia zrównoważonego rozwoju w budownictwie. Na podstawie przeglądu dostępnej literatury można stworzyć listę odpadowych tworzyw sztucznych, które zastosowano jako modyfikatory betonów i zapraw: tworzywo ABS (kopolimer akrylonitryl-butadien-styren) [4], pianka poliuretanowa [5-7], ekspandowany polistyren i polistyren [8-10], polietylen o małej i dużej gęstości oraz polipropylen i poli(chlorek winylu) [11-14], żywice melaminowo-formaldehydowe [15], poli(tereftalan etylenu) [16-20]. Modyfikacją tą objęto przede wszystkim kompozyty cementowe. W niniejszym artykule przedstawiono porównanie wybranych właściwości zapraw żywicznych zawierających odpady tworzyw sztucznych. 


\section{Opis procedury badawczej}

\subsection{Użyte surowce i metody otrzymywania zaprawy żywicznej}

Zaprawy żywiczne wykonano z zastosowaniem żywicy epoksydowej Epidian 5, utwardzacza Z-1, piasku normowego o uziarnieniu 0 - $2 \mathrm{~mm}$ oraz czterech różnych rodzajów odpadowych tworzyw sztucznych (Rys. 1): polietylenu (PE), polipropylenu (PP), pianki poliuretanowej (PU) oraz ekspandowanego polistyrenu (EPS).
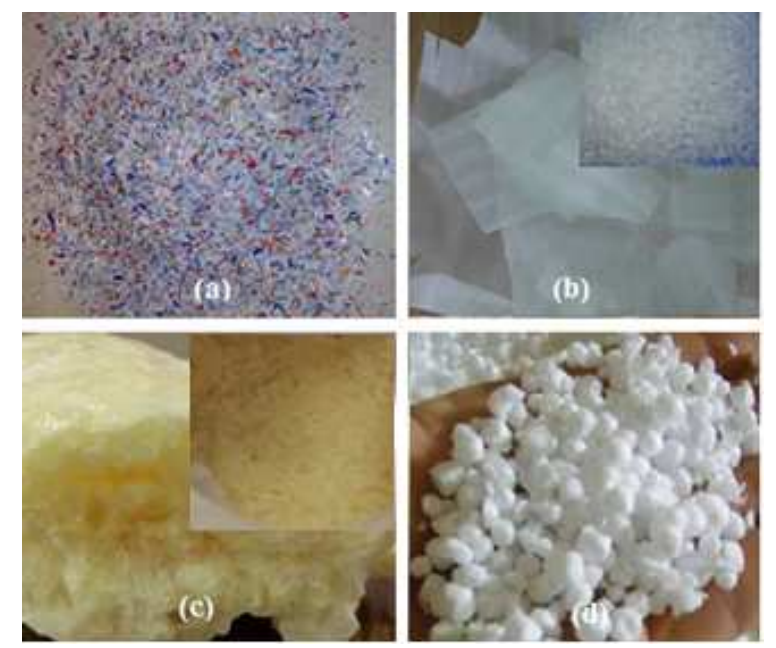

Rys. 1. Odpady zastosowane do otrzymania zapraw epoksydowych, a) PP, b) PE, c) PU, d) EPS

Fig. 1. Waste used to obtain the epoxy mortars, a) PP, b) PE, c) PU, d) EPS

Odpady te pochodziły odpowiednio z kubków po jogurtach, pianki podkładowej pod panele, pianki montażowej oraz płyt styropianowych. Odpady po rozdrobnieniu stanowiły substytut piasku normowego (pakowanego w woreczki) w ilości odpowiednio $0 \%, 5 \%, 10 \%, 15 \%$ i $20 \%$ obj. Zachowano stałą proporcję żywicy do kruszywa (piasku wraz z materiałem odpadowym) na poziomie 0,25 . Utwardzacz dozowano w ilości 10\% wagowych w stosunku do masy żywicy.

\section{Metodyka i wyniki badań}

Odpowiedni rodzaj materiału odpadowego oraz piasek odważono przy użyciu wagi technicznej. Następnie wymieszano obydwa komponenty. Żywicę epoksydową odważono w zlewce. Po przygotowaniu odpowiednich ilości żywicy epoksydowej oraz kompozycji kruszyw, do zlewki z żywicą epoksydową dolano odpowiednią ilość utwardzacza Z-1 (10 cz. w./100 g żywicy). Składniki 
następnie dokładnie wymieszano przy pomocy szklanej bagietki, aż do uzyskania jednorodnej mieszaniny. Do misy mieszarki laboratoryjnej przeniesiono przygotowaną kompozycję żywicy z utwardzaczem i wymieszano z kruszywem oraz materiałem odpadowym, zachowując jednakowy czas mieszania i obroty mieszarki. Gotową zaprawę umieszczono w formach stalowych o wymiarach: 40x40x160 mm (próbki przeznaczone do badań wytrzymałościowych) oraz 60x60x5 mm (próbki do badań nasiąkliwości). Aby nastąpił proces utwardzenia, próbki pozostawiono przez $7 \mathrm{dni}$ w pojemnikach polipropylenowych w warunkach laboratoryjnych.

Dla utwardzonych zapraw epoksydowych wykonano oznaczenia następujących właściwości:

a) Wytrzymałości: na zginanie $\mathrm{f}_{\mathrm{f}}$ i na ściskanie $\mathrm{f}_{\mathrm{c}}$.

Badania te przeprowadzono $\mathrm{w}$ maszynie wytrzymałościowej zaopatrzonej w odpowiednie wkładki, na beleczkach normowych zgodnie z normą PN-EN 196-1:2006.

b) Gęstości objętościowej zgodnie z normą PN-85/B-04500:1985.

c) Absorpcji wody zgodnie z normą PN-EN ISO 175:2002.

Wyniki badań wytrzymałościowych oraz gęstości objętościowej próbek zapraw epoksydowych zawierających poszczególne typy odpadów przedstawiono odpowiednio na rysunkach 2-4.

Do opisu różnic w poziomie nasiąkliwości próbek wykorzystano funkcję logarytmiczną o równaniu:

$$
\mathrm{z}=\mathrm{a}+\mathrm{b} \cdot \ln (\mathrm{x})
$$

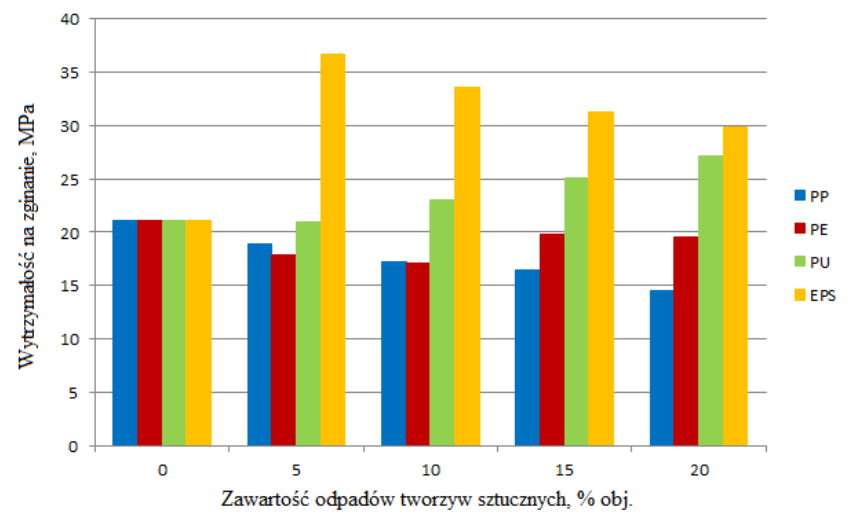

Rys. 2. Zależność wytrzymałości na zginanie od rodzaju i procentowej zawartości materiału odpadowego

Fig. 2. The dependence the flexural strength of the type and percentage content of waste material 


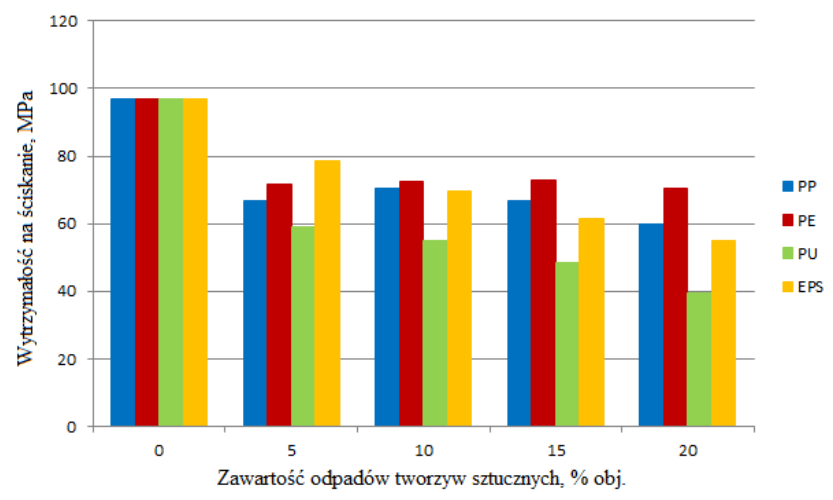

Rys. 3. Zależność wytrzymałości na ściskanie od rodzaju i procentowej zawartości materiału odpadowego

Fig. 3. The dependence the compressive strength of the type and percentage content of waste material

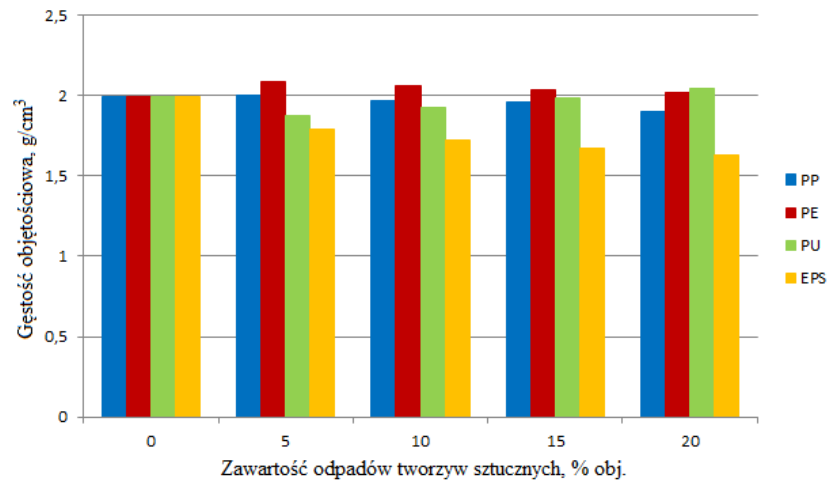

Rys.4. Zależność gęstości objętościowej od rodzaju i procentowej zawartości materiału odpadowego

Fig. 4. The dependence the volume density of the type and percentage content of waste material

Uzyskane w ten sposób wykresy funkcji trendu dla próbek zapraw modyfikowanych za pomocą omawianych odpadów tworzyw sztucznych przedstawiono na rysunku 5. Nasiąkliwość wzrasta wraz ze wzrostem czasu trwania zanurzenia. O sile tej zależności świadczą uzyskane współczynniki determinacji zawarte w tabeli 1. Tabela ta zawiera także wartości współczynników krzywej regresji obliczonych dla przyjętej logarytmicznej funkcji trendu. 


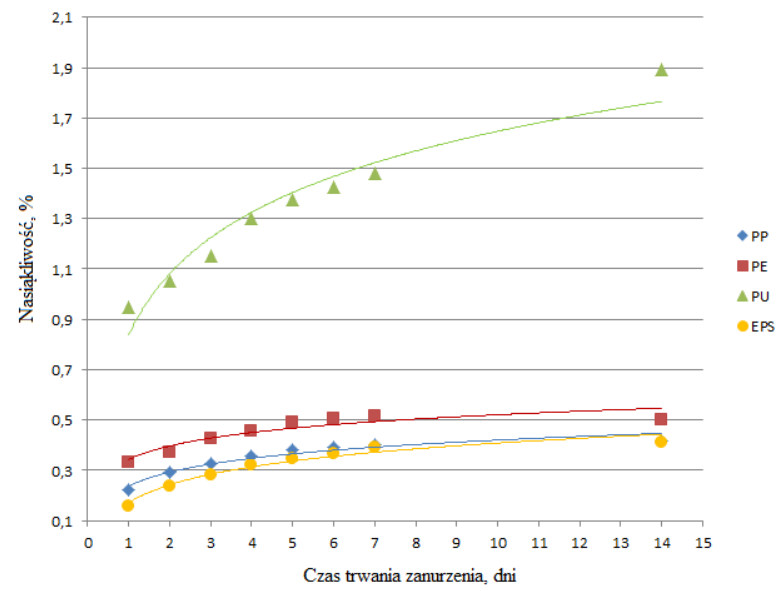

Rys.5. Zależność nasiąkliwości od czasu trwania ekspozycji w wodzie i rodzaju materiału odpadowego

Fig. 5. The dependence the water absorption of the duration of exposure in water and the type of waste material

Tabela 1. Zestawienie parametrów krzywych regresji oraz współczynników determinacji opisujących zmianę nasiąkliwości próbek w zależności od rodzaju materiału odpadowego

Table 1. Selection of the parameters of the regression curves and determination coefficients describing the change of absorption of samples depending on the type of waste material

\begin{tabular}{|c|c|c|c|c|}
\hline \multirow{2}{*}{$\begin{array}{c}\text { Współczynnik regresji/ } \\
\text { współczynnik determinacji }\end{array}$} & \multicolumn{4}{|c|}{ Nasiąkliwość } \\
\cline { 2 - 5 } & PP & PE & PU & EPS \\
\hline $\mathrm{a}$ & 0,0793 & 0,0770 & 0,3515 & 0,1030 \\
\hline $\mathrm{b}$ & 0,2373 & 0,3431 & 0,8379 & 0,1708 \\
\hline $\mathrm{R}^{2}$ & 0,9421 & 0,8552 & 0,9339 & 0,9633 \\
\hline
\end{tabular}

\section{Analiza wyników}

Rodzaj zastosowanego materiału odpadowego znacznie różnicuje oznaczane parametry badanych próbek zapraw.

\subsection{Wytrzymałość na zginanie}

Najniższe wartości wytrzymałości na zginanie uzyskano dla próbek zapraw zawierających $15 \%$ i $20 \%$ odpadów polipropylenu. Wytrzymałość ta maleje wraz ze wzrostem zawartości modyfikatora. Podobna zależność ma miejsce również w przypadku odpadów PE, jednak przy $15 \%$ i $20 \%$ dodatku widoczny jest nieznaczny wzrost badanego parametru do poziomu $20 \mathrm{MPa}$, zbliżonego do 
wytrzymałości na zginanie zapraw niemodyfikowanych. Wytrzymałość na zginanie zapraw epoksydowych z dodatkiem odpadów pianki poliuretanowej rośnie wraz ze wzrostem zawartości modyfikatora. W przypadku $20 \%$ substytucji piasku przez PU, wytrzymałość wynosi 27,12 MPa i jest o 6 MPa wyższa niż dla zapraw niemodyfikowanych. Zdecydowanie najwyższe wartości wytrzymałości na zginanie udało się uzyskać dla próbek zapraw zawierających odpadowy EPS. Najwyższą wartością oznaczanego parametru równą 36,69 MPa, charakteryzują się zaprawy z 5\% dodatkiem odpadu EPS. Jest to wynik o prawie $74 \%$ wyższy od uzyskanego dla zapraw niemodyfikowanych. Zwiększanie ilości modyfikatora powoduje obniżenie wytrzymałości, jednak nawet przy $20 \%$ zawartości EPS jest ona bardzo wysoka i wynosi 29,86 MPa.

\subsection{Wytrzymałość na ściskanie}

Dodatek każdego z omawianych odpadów tworzyw sztucznych powodował znaczne obniżenie wytrzymałości na ściskanie zapraw epoksydowych. Najniższe wartości odnotowano dla zapraw modyfikowanych pianką PU. Przy $20 \%$ jej dodatku wytrzymałość zmalała do 39,39 MPa. Wytrzymałość na ściskanie maleje także wraz ze wzrostem zawartości odpadów EPS, jednak przy 5\% substytucji piasku, wytrzymałość ta jest najwyższa wśród wszystkich zapraw modyfikowanych i wynosi 78,74 MPa. Dodatek PP i PE również powoduje obniżenie wartości oznaczanego parametru, jednak zwiększenie ilości dodawanego odpadu tylko nieznacznie wpływa na zmianę wartości wytrzymałości na ściskanie.

\subsection{Gęstość objętościowa}

Dodatek odpadów PP i EPS powoduje obniżenie gęstości objętościowej zapraw. Najlżejszą zaprawę udało się otrzymać dla zapraw o $20 \%$ substytucji piasku przez odpady EPS. W tym przypadku gęstość objętościowa wynosiła $1,627 \mathrm{~g} / \mathrm{cm}^{3}$ i była niższa o $18,36 \%$ od gęstości objętościowej zaprawy niemodyfikowanej.

\subsection{Nasiąkliwość}

Dla każdego z czterech zastosowanych odpadów zaobserwowano wzrost nasiąkliwości badanych próbek zapraw w czasie trwania ich ekspozycji w wodzie. Analizując funkcje trendu zaprezentowane na rysunku 5 zauważa się, że różnice nasiąkliwości występujące dla odpadów PP i EPS a PE są nieznaczne. Funkcje trendu uzyskane dla zapraw z dodatkiem odpadów PP i EPS są bardzo zbliżone, a w drugim tygodniu ekspozycji praktycznie się pokrywają. Wyniki uzyskane podczas modyfikacji zapraw odpadami pianki poliuretanowej znacznie odbiegają od pozostałych. Zdecydowanie najwyższe wartości nasiąkliwości uzyskano dla zapraw zawierających odpady PU. Po 14 dniach ekspozycji próbek w wodzie średnia nasiąkliwość wyniosła $1,9 \%$. Znacznie niższe wartości nasią- 
kliwości, na poziomie $0,41 \%$, oznaczone również po 14 dniach zanurzenia, odnotowano w przypadku próbek zapraw zawierających odpady PP i EPS. Po tym czasie ekspozycji były to najniższe $\mathrm{z}$ obserwowanych wartości. 14 dniowa nasiąkliwość próbek zapraw, otrzymanych po zastosowaniu odpadów PE, lokowała się pomiędzy wynikami opisanymi dla pozostałych rodzajów odpadów i wynosiła $0,5 \%$. Na uzyskane wyniki nasiąkliwości ma wpływ porowatość zapraw, a także samego materiału odpadowego. Styropian oraz polipropylen to materiały o strukturze bardzo odpornej na działanie wody. Z kolei polietylen $\mathrm{w}$ formie pianki posiada dodatkowe wolne przestrzenie, które może wypełnić woda. Najbardziej porowata jest pianka poliuretanowa (PU) i dodana do zapraw powoduje znaczny wzrost ich nasiąkliwości.

\section{Wnioski}

Na podstawie przeprowadzonych badań można sformułować następujące wnioski:

- Zastosowanie odpadów PP i PE powoduje spadek wytrzymałości na zginanie zapraw epoksydowych. Natomiast wytrzymałość na zginanie zapraw zawierających odpady PU i EPS jest wyższa niż dla zapraw niemodyfikowanych. Najwyższą wartością tej wytrzymałości, równą $36,69 \mathrm{MPa}$, cechowały się próbki zawierające $5 \%$ obj. EPS.

- Dodatek każdego z odpadowych tworzyw sztucznych znacznie obniżał wytrzymałość na ściskanie zapraw epoksydowych. Największe różnice zaobserwowano po dodaniu do kompozytu pianki poliuretanowej (PU). Jednak uzyskane wartości wytrzymałości na ściskanie należące do przedziału 39,39 MPa - 78,74 MPa, są nadal bardzo wysokie.

- Największe różnice w gęstości objętościowej obserwowano w przypadku zapraw modyfikowanych odpadami EPS. Przy 20\% substytucji piasku przez to tworzywo, gęstość objętościowa uległa zmniejszeniu o 18,36\% w stosunku do wartości tego parametru zapraw niemodyfikowanych.

- Modyfikowane zaprawy cechowała bardzo niska nasiąkliwość, szczególnie te zawierające odpady PP, PE i EPS. Po 14 dniach zanurzenia w wodzie parametr ten osiągnął wartość $0,5 \%$.

- Zastosowanie odpadów tworzyw sztucznych do otrzymywania zapraw żywicznych pozwala uzyskać kompozyty cechujące się dobrymi parametrami fizykomechanicznymi, a jednocześnie stanowi jeden ze sposobów utylizacji tych uciążliwych dla środowiska odpadów. 


\section{Literatura}

[1] Panda A.K., Singh R.K., Mishra D.K.: Thermolysis of waste plastics to liquid fuel. A suitable method for plastic waste management and manufacture of value added products - A world prospective, Renewable and Sustainable Energy Reviews, vol. 14, 2010, pp. 233-248.

[2] Siddique R., Khatib J., Kaur I.: Use of recycled plastic in concrete: A review, Waste Management, vol. 28, 2008, pp. 1835-1852.

[3] Kozłowski M. [red.], Podstawy recyklingu tworzyw sztucznych, Wydawnictwo Politechniki Wrocławskiej, 1998.

[4] Palos A., D’Souza N.A., Snively C.T., Reidy III R.F.: Modification of cement mortar with recycled ABS, Cement and Concrete Research, vol.31, 2001, pp. 1003-1007.

[5] Corinaldesi V., Mazzoli A., Moriconi G.: Mechanical behaviour and thermal conductivity of mortars containing waste rubber particles, Materials and Design, vol. 32, 2011, pp. 1646-1650.

[6] Fraj A.B., Kismi M., Mounanga P.: Valorization of coarse rigid polyurethane foam waste in lightweight aggregate concrete, Construction and Building Materials, vol. 24, 2010, pp. 1069-77.

[7] Mounanga P., Gbongbon W., Poullain P., Turcry P.: Proportioning and characterization of lightweight concrete mixtures made with rigid polyurethane foam wastes, Cement and Concrete Composites, vol. 30, 2008, pp. 806-814.

[8] Amianti M., Botaro V.R.: Recycling of EPS: A new methodology for production of concrete impregnated with polystyrene (CIP), Cement and Concrete Composites, vol. 30, 2008, pp. 806-814.

[9] de Assunção R.M.N., Royer B., Oliveira J.S., Filho G.R., de Castro Motta L.A.: Synthesis, characterization and application of the sodium poly(styrenesulfonate) produced from waste polystyrene cups as an admixture in concrete, Journal of Applied Polymer Science, vol. 96, 2005, pp. 1534-1538.

[10] Laukaitis A., Žurauskas R., Kerienè J.: The effect of foam polystyrene granules on cement composites properties, Cement and Concrete Composites, vol. 27, 2005, pp. 41-47.

[11] Pešic' N., Z $Z^{\vee}$ ivanovic' S., Garcia R., Papastergiou P.: Mechanical properties of concrete reinforced with recycled HDPE plastic fibres, Construction and Building Materials, vol. 115, 2016, pp. 362-370.

[12] Ruiz-Herrero J.L., Velasco Nieto D., López-Gil A., Arranz A., Fernández A., Lorenzana A., Merino S., De Saja J.A., Rodríguez-Pérez M.A.: Mechanical and thermal performance of concrete and mortar cellular materials containing plastic waste, Construction and Building Materials, vol. 104, 2016, pp. 298-310.

[13] Galvão J.C.A., Portella K.F., Joukoski A., Mendes R., Ferreira E.S.: Use of waste polymers in concrete for repair of dam hydraulic surfaces, Constructions and Building Materials, vol. 25, 2011, pp. 1049-1055.

[14] Kou S.C., Lee G., Poon C.S., Lai W.L.: Properties of lightweight aggregate concrete prepared with PVC granules derived from scraped PVC pipes, Waste Management, vol. 29, 2009, pp. 621-628. 
[15] Panyakapo P., Panyakapo M.: Reuse of thermosetting plastic waste for lightweight concrete, Waste Management, vol. 28, 2008, pp. 1581-1588.

[16] Nikbin, I.M., Rahimi S., Allahyari A., Fallah F.: Feasibility study of waste Poly Ethylene Terephthalate (PET) particles as aggregate replacement for acid erosion of sustainable structural normal and lightweight concrete, Journal of Cleaner Production, 2016, http://dx.doi.org/10.1016/j.jclepro.2016.02.143

[17] Dębska B., Lichołai L.: The selected mechanical properties of epoxy mortar containing PET waste, Construction and Building Materials, vol. 94, 2015, pp.579-588.

[18] Dębska B., Lichołai L.: A study of the effect of corrosive solutions on selected physical properties of modified epoxy mortars, Construction and Building Materials, vol.65, 2014, pp. 604-611.

[19] Dębska B.: Modification of Polymer Composites by Polyethylene Terephthalate Waste, Poly(ethylene Terephthalate) Based Blends, Composites and Nanocomposites (Book), Visakh P.M., Liang M. red., Elsevier Inc., 2015, pp.195-212.

[20] Dębska, B., Lichołai, L.: Resin Composites with High Chemical Resistance for Application in Civil Engineering, Periodica Polytechnica Civil Engineering, DOI:10.3311/PPci.7744.

\title{
THE COMPARISON OF THE SELECTED PROPERTIES OF POLYMER MORTARS CONTAINING PLASTIC WASTE
}

\begin{abstract}
S u m m a r y
Rational waste management is one of the priority directions of the widely understood environmental protection. The fact of the skillful management of waste is also important in the context of sustainable development of societies. Plastics are the extremely harmful waste to the environment. Increasing constantly amounts of such waste cause the occurrence of problems both ecological and economic, which is associated with poor biodegradation plastics. Waste has been used for the production of building materials. Research on the waste management of plastics are currently conducted in various scientific centers in the world. In the literature can be find descriptions of the use of waste, among others, polyethylene and polypropylene, polystyrene, polyurethane, polycarbonate, polyamide, or poly (vinyl chloride), as modifiers of cement concrete and mortars. This article presents the results of the comparison of selected properties of four series of resin mortars containing different plastic waste, i.e. .: polypropylene (PP), polyethylene (PE) foam polyurethane (PU) and expanded polystyrene (EPS). These wastes come from yoghurt cups, foam under the panels, mounting foam and polystyrene panels. They were fragmented and represented a partial replacement aggregate in mortars epoxy. Such mortars were tested as flexural strength and compressive strength, bulk density and water absorption.
\end{abstract}

Keywords: epoxy mortars, plastic waste, mechanical properties, absorbability

DOI:10.7862/rb.2016.251

Przestano do redakcji: $23.05 .2016 r$.

Przyjęto do druku: 20.12.2016 r. 